\title{
Kidney affectation in non-complicated high blood pressure patients
}

\author{
Dr. Gilberto Cairo Sáez, PhD ${ }^{1 *}$, Dr. René Miguel Pérez Rodríguez ${ }^{2}$ and Dr. Vilma Ferrer Suarez²
}

\begin{abstract}
Gilberto CS, René PR, Vilma FS. Kidney affectation in non-complicated high blood pressure patients. Curr Res Cardiol 2017;4(4):65-68.

INTRODUCTION: High blood pressure is a very frequent condition that deteriorates the so calls target organs: brain, heart and kidney. Objective: to identify the level of renal affectation in non-complicated hypertensive patients.

PATIENTS AND METHODS: A transversal descriptive study was designed in "José Marti" community in Santa Clara; it included a random sample of 47 patients (15\%) from a universe of 311 hypertensive patients without evidences of clinical complications. Plasma glucose, creatinine, cholesterol, triglycerides, and uric acid were measured; urinary sediment microscopy was performed as well as search for microalbuminuria. Echocardiogram and funduscopy were performed to all cases.
\end{abstract}

RESULTS AND DISCUSSION:The majority of patients were white women and the most frequent risk factors were overweight, hypertensive retinopathy grade I or II, the non-white color of the skin and left ventricular hypertrophy. The microalbuminuria was positive in eight patients $(17 \%)$ while $27(51.1 \%)$ had a creatinine clearance less than $90 \mathrm{ml} / \mathrm{min} / \mathrm{m}^{2}$ BS and $13(27.3 \%)$ less than $60 \mathrm{ml} / \mathrm{min} / \mathrm{m}^{2} \mathrm{BS}$, there were evidences of Hypertensive Heart Disease in $36(76.5 \%)$ patients, of them $11(23.4 \%)$ showed evidences of left atrial dilation, $80 \%$ had evidences of renal dysfunction in spite of having normal creatinine, the only variable that correlated significantly with renal affectation was the illness evolution time $(\mathrm{p}<0.05)$.

CONCLUSION: Hypertensive patients even without evidences of clinical complications had a hidden kidney affectation, longer evolution of hypertension increases the frequency of renal function decline.

Key Words: Chronic kidney disease; Hypertension; Risk factors
$\mathrm{H}$ igh blood pressure (HBP) has a world prevalence of $33.7 \%$ in adult population, before the age of 50 prevalence of HBP is a little lower in females than in males, this suggests a protector effect of estrogens. After the menopause, the hypertension increases quickly in women and it overcomes that of men. In United States 33\% of Afro-American population has hypertension, in comparison with $25 \%$ of those of white and MexicanAmericans, in Latin America 140 million people suffer of $\operatorname{HBP}(1,2)$.

In Cuba HBP has increased its prevalence and it represented the $38 \%$ of people older than 18 years-old in 2016, in that very year the HBP prevalence rate in Villa Clara province was 227.6 per 1000 inhabitant (3). In Santa Clara municipality, at the end of 2015, 46,000 people suffering HBP were reported. In "José Marti" community there was 2,042 hypertensive patients of them 1,050 women and 992 men.

The public health indicators at world level and in Cuba, shows a progressive increase of the number of patients with chronic kidney disease (CKD) associated to a high prevalence of chronic illness as HBP. The CKD can progress to terminal renal disease and implicates a higher risk of cardiovascular illness and mortality, therefore, prevention through early diagnosis and opportune treatment, would allow stopping or retarding the progression of the renal damage and it would diminish its morbidity and mortality.

In a meeting in the National Center of Cardiovascular Investigations of Madrid about the necessity of detection and early intervention on CKD, a very unknown illness in their initial phases, of which data fundamentally comes from studies in their very advanced stages, there was agreement that it is a mistake to speak only about the heart not realizing that other organs are affected by the same risk factors (RF) that can be modified. Participants in the meeting consider that early detection of renal affectation would avoid the costs of assisting an increasing number of patients with renal illness in advanced stages (4).

The NHANES III study (5) emphasized that the $4.7 \%$ of the population older than 20 years-old has a creatinine clearance under $60 \mathrm{ml} / \mathrm{min} / \mathrm{m}^{2} \mathrm{BS}$. In Spain Hill et al. (6) report a 13\% prevalence but in a population older than 64 years-old it can reach $49 \%(7,8)$.

It has been demonstrated that the relative risk of suffering chronic nephropathy when isolated HBP exists is 1.57 (9). The CKD in most cases is asymptomatic in its initial stages. Usually, detection takes place in a routine analytic control of plasmatic creatinine that is performed periodically in hypertensive patients in primary health care. However many cases are overlook because their doctors only consider the absolute values of creatinine in the evaluation of these patients and many cases in their initial stages are asymptomatic and have normal figures of creatinine when the filtrate has already fallen below $90 \mathrm{ml} / \mathrm{min} / \mathrm{m}^{2}$ BS. Previous studies suggest that hidden CKD was frequent in "Jose Marti" community (10). The present investigation was design to determining the level of renal affectation in non-complicated HBP patients; this information would allow establishing strategies to prevent the progression from the HBP to CKD.

\section{METHODS}

A descriptive, transversal and observational study was designed to detect unidentified presence of renal affectation in non-complicated hypertensive patients in "José Marti" community of Santa Clara, Villa Clara, Cuba, between January 2016 and January 2017. From a universe of 2041 hypertensive patients older than 18 years-old, 311 had no evidences of complications; a $15 \%$ random stratify sample was taken from the eight clinics of the community, it was integrated by 47 patients. Plasma glucose, creatinine, cholesterol, triglycerides, and uric acid were measured; urinary sediment microscopy was performed as well as search for microalbuminuria in patients with normal urinalyses. Funduscopy searching for hypertensive retinopathy and echocardiogram was performed in all cases. The personal data included, age, sex, color of the skin and time of evolution of the HBP starting from the diagnosis.

Echocardiographic variables used to find evidence of Hypertensive Heart Disease were: left ventricle relaxation pattern, wall thickness index greater than 0.42 (calculated as 2 times left posterior wall/left ventricle internal diastolic diameter), Left Atrium indexed volume higher than $34 \mathrm{ml} / \mathrm{m}^{2}$ of body surface (BS) and the presence of left ventricle hypertrophy (LVH) consider as a cardiac mass more than $95 \mathrm{~g} / \mathrm{m}^{2}$ BS for women or more than $115 \mathrm{~g} / \mathrm{m}^{2}$ BS for men. (LV mass $=0.8 \times 1.04 \times[(I V S+L V I D+P W T) 3$ - LVID3) $+0.6 \mathrm{~g}$ ). The presence of urine albumin and microalbuminuria, or the reduction of creatinine clearance calculated by the Cockcroft - Gault formula, were considered evidence of kidney affectation; patients were classified according to the guides of the Kidney Diseases Outcomes Quality Initiative (11).

\footnotetext{
${ }^{1}$ Internal Medicine Specialist, Villa Clara Medical University (UCMVC), Cuba, ${ }^{2}$ Family Physician. Villa Clara Medical University (UCMVC), Cuba

Correspondence: Dr Gilberto Cairo Sáez, Internal Medicine Specialist, Villa Clara Medical University (UCMVC), Section Editor Medicentro Electronica ave 7 diciembre 202, Santa Clara, Villa Clara 50100 Cuba. Telephone+5353206630, e-mail cairos@infomed.sld.cu

Received: November 12, 2017, Accepted: November 27, 2017, Published: November 29, 2017

This open-access article is distributed under the terms of the Creative Commons Attribution Non-Commercial License (CC BY-NC) (http://
OPEN
creativecommons.org/licenses/by-nc/4.0/), which permits reuse, distribution and reproduction of the article, provided that the original work is
properly cited and the reuse is restricted to noncommercial purposes. For commercial reuse, contact reprints@pulsus.com
} 
Subclinical or asymptomatic renal damage was considered when estimated GFR was between $30-60 \mathrm{ml} / 1.73 \mathrm{~m}^{2} \mathrm{BS}$ or microalbuminuria $(30-300 \mathrm{mg} / 24$ h), or albumin-creatinine ratio (30-300 mg/g; $3.4-34 \mathrm{mg} / \mathrm{mmol})(12)$.

It was considered adequate treatment when patients with moderate risk were receiving at least two drugs including a diuretic and three drugs when they were at high risk, also including a diuretic. The risk was considered according the 2013 European Society of Hypertension/European Society of Cardiology Guidelines for the management of arterial hypertension (12).

It was considered a good blood pressure (BP) control when there were normal figures of $\mathrm{BP}$ in at least the last three clinic controls, without urgencies, emergencies or decompensating episodes during the year previous to the study entrance.

\section{DATA RECOLLECTION}

Data was collected in Ad Hoc form, tabulated with Microsoft Excel 2013 and processed with the statistical package SPSS for Windows 20.0.

\section{STATISTICAL ANALYSIS}

A logistical regression that included all variables was done, with renal affectation as dependent variable. Some variables of interest were analyzed to find out correlation with low creatinine clearance, finally, absolute and relative frequencies were used for description of qualitative variables.

\section{ETHICAL CONSIDERATIONS}

All the patients were informed of the purposes of the study and it was guaranteed their privacy and the use of data exclusively for scientific matter and they were verbally requested their consent to be included in the investigation.

\section{RESULTS}

Sample age average was 64 years \pm 10 and the average of evolution time of HBP was 11.4 years. Distribution by sex and skin color appears in Table 1, in which it can be seen that white women were predominant.

\section{TABLE 1}

Distribution of non-complicated hypertensive patients by skin color and sex

\begin{tabular}{ccccccc}
\hline \multirow{2}{*}{ Sex } & \multicolumn{2}{c}{ Whites } & \multicolumn{2}{c}{ Non-withes } & \multicolumn{2}{c}{ Total } \\
\cline { 2 - 7 } & No. & $\%$ & No. & $\%$ & No. & $\%$ \\
\hline Males & 9 & 61.5 & 5 & 38.5 & 14 & 29.8 \\
\hline Females & 19 & 57.1 & 14 & 42.9 & 33 & 70.2 \\
\hline Total & 28 & 59.6 & 19 & 40.4 & 47 & 100 \\
\hline
\end{tabular}

Source: Queries

Of the studied patients $63.9 \%$ were overweight with a body mass index (BMI) over $25 \mathrm{Kg} / \mathrm{m} 2$ and from them $10(24.3 \%)$ were obese (BMI $>30 \mathrm{Kg} /$ $\mathrm{m} 2)$ as seen in Table 2.

TABLE 2

Risk factors in non-complicated hypertensive patients

\begin{tabular}{ccc}
\hline Risk factor & No. & $\%$ \\
\hline Overweight $\left(\mathrm{BMI} 25-30 \mathrm{~kg} / \mathrm{m}^{2}\right)$ & 20 & 42.6 \\
Obese $\left(\mathrm{BMI}>30 \mathrm{~kg} / \mathrm{m}^{2}\right)$ & 10 & 21.3 \\
Subtotal $\left(\right.$ Patients with BMI $\left.>25 \mathrm{Kg} / \mathrm{m}^{2}\right)$ & 30 & 63.9 \\
Abnormal funduscopy & 24 & 51.1 \\
Non-white color of the skin & 19 & 40.4 \\
Left ventricle hypertrophy or remodeling & 15 & 31.9 \\
Triglycerides $>2.1$ & 11 & 23.4 \\
Diabetes mellitus & 2 & 4.8 \\
\hline
\end{tabular}

BMI: Body Mass Index; Source: Queries and clinical files

There were only two diabetic patients $4.8 \%$. In 24 patients there was retinopathy in the funduscopy, although in no case it was more than grade II. Of the 15 patients with LVH or remodeling of left ventricle, 12 (80\%) had a creatinine clearance under $90 \mathrm{ml} / \mathrm{min} / \mathrm{m}^{2}$ BS.

There were evidences of Hypertensive Heart Disease in 36 (76.5\%) patients, of them 11 (23.4\%) had evidences of dilation of the Left Atrium with an indexed volume higher $34 \mathrm{ml} / \mathrm{m}^{2}$ BS, 11 presented LVH and other four even without LVH had a relative wall thickness greater than 0.42 (Table 2), although there was any patient with serious hypertensive retinopathy (grade
III, IV) 29 patients (61.7\%) had alterations in the funduscopy classify as grade I or II retinopathy, 25 of them $(86.2 \%)$ had a creatinine clearance at least below $90 \mathrm{ml} / \mathrm{min} / \mathrm{m}^{2} \mathrm{BS}$.

The Table 3 shows the evidences of renal affectation, it was found $13(27.3 \%)$ patients with CKD grade III but other 24 patients $(51.1 \%$ ) had a calculated filtrate below $90 \mathrm{ml} / \mathrm{min} / \mathrm{m}^{2}$ BS, and there was a patient with positive microalbuminuria and normal creatinine clearance, so that 38 patients (80.8\%) had evidences of renal involvement.

\section{TABLE 3}

Evidence of renal affectation in non-complicated hypertensive patients

\begin{tabular}{|c|c|c|}
\hline Parameter & No & $\%$ \\
\hline Microalbuminuria (> 30 mg/L) & 8 & 17 \\
\hline $\begin{array}{c}\text { Creatinine clearance between } 60 \\
\text { and } 89 \mathrm{ml} / \mathrm{min} / \mathrm{m}^{2} \text { BS }\end{array}$ & 24 & 51.1 \\
\hline $\begin{array}{l}\text { Creatinine clearance }<60 \mathrm{ml} / \mathrm{min} / \\
\mathrm{m}^{2} \mathrm{BS}\end{array}$ & 13 & 27.3 \\
\hline Total & 38 & 80.8 \\
\hline
\end{tabular}

Source: Queries

The microalbuminuria was positive in eight $(17.0 \%)$ patients, none of which had a previous diagnosis of renal affectation before entering the study and seven of them had a creatinine clearance below $90 \mathrm{ml} / \mathrm{min} / \mathrm{m}^{2}$ BS. Most of the cases were classified as low or moderate risk patients, only $21.27 \%$ were classify as high-risk patients. After considering the presence of asymptomatic organ damage, according to the evidences of the study, 37 (78.72\%) patients were re-stratified as high risk.

In Table 4 it can be seen, that after considering the evidence provided for the evaluation performed to the patients during the investigation, the new stratification yielded that most patients could be classified as high-risk patients.

\section{TABLE 4}

Total cardiovascular risk in non-complicated hypertensive patients with and without renal affectation before and after the study evaluation

\begin{tabular}{ccccccccc}
\hline & \multicolumn{3}{c}{ Risk before study evaluation } & \multicolumn{3}{c}{$\begin{array}{c}\text { Risk after the study } \\
\text { evaluation }\end{array}$} \\
\cline { 2 - 9 } Risk & \multicolumn{2}{c}{$\begin{array}{c}\text { with renal } \\
\text { affectation }\end{array}$} & $\begin{array}{c}\text { without renal } \\
\text { affectation }\end{array}$ & $\begin{array}{c}\text { with renal } \\
\text { affectation }\end{array}$ & $\begin{array}{c}\text { without renal } \\
\text { affectation }\end{array}$ \\
\cline { 2 - 9 } & No. & $\%$ & No. & $\%$ & No. & $\%$ & No. & $\%$ \\
\hline Low & 8 & 80 & 2 & 20 & 2 & 50 & 2 & 50 \\
Moderate & 21 & 77.7 & 6 & 22.3 & 4 & 66.7 & 2 & 33.3 \\
High & 9 & 90 & 1 & 10 & 32 & 86.5 & 5 & 13.5 \\
Total & 38 & 80.8 & 9 & 19.2 & 38 & 80.8 & 9 & 19.2 \\
\hline
\end{tabular}

Source: Queries and clinical files

At the entrance in the study the evidence of renal involvement was similar in low and high-risk patients but after a proper evaluation there was a higher proportion of renal affectation between high risk patients, even when the difference was not significant.

A logistic regression including all variables in the study did not yield any useful predictor model. The only variable that shows significant correlation with the renal damage was the evolution time from the initial diagnosis of HBP $\mathrm{p}<0.01$.

According to the criteria used to evaluate the treatments they were appropriate in $29(61.7 \%)$, with the data available at the entrance in the study, but after the evidence offered for the evaluation performed during the investigation, this figure was reduced to only 11 patients (23.4\%). Nevertheless 41 (87.2\%) patients were in good control, according to BP figures.

\section{DISCUSSION}

Most patients were white women, this could have, partly, a demographic explanation since in the province the hypertension is more frequent in women than in men $(3,13)$, so the results agree with the statistic of the latest RF survey, however other studies have shown different sex distribution, an investigation carried out in the adult population of the city of Chiclayo in Peru, that included 322 patients, found that the prevalence of HBP was $29.2 \%$ for the whole population, $30.7 \%$ for the males and $28.6 \%$ for women (14). Ortiz Brown et al. (15) investigated the prevalence of HBP in Madrid, Spain and they found a higher prevalence in men that in women, 35.1\% and 


\section{$23.9 \%$ respectively}

The most frequent RF in the study was overweight or obesity. ACCOMPLISH (16) a randomized multicenter controlled study, that included 11482 hypertensive patients also found that a significant number of patient were overweight and obese in comparison with the non-hypertensive population, the investigators considered that it could be explained because patients with a higher BMI have an increased sensibility to sodium and a decreased excretion of the exogenous load of the ion, that predisposes patients to develop hypertension and increases deleterious effects of HBP on the target organs (17). Other authors have found similar results and coincide in the possible relationship with the excess of sodium (18).

Funduscopy was positive for retinopathy in half of the patients, although it was mild, since it never was more than grade II, those early alterations in the retina of hypertensive patients may be pointing out the necessity of readjustments in treatment. Microalbuminuria was not very frequent in this study, Curto and Prats (2) studied 150 non-complicated hypertensive patients of which $65 \%$ were at some stage of CKD according to the estimated GFR and only $20 \%$ had positive microalbuminuria, Echeverría (18) reported similar results in his study of prevalence of HBP and damage of target organs, $70 \%$ of the hypertensive patients had renal damage and only $18 \%$ had positive microalbuminuria. Although there is agreement considering renal damage when there is a reduction of the creatinine clearance below $60 \mathrm{ml} /$ $\mathrm{min} / \mathrm{m}^{2} \mathrm{BS}$, if it is considered that a decrease below $90 \mathrm{ml} / \mathrm{min} / \mathrm{m}^{2}$ already implies a reduction of normal filtrate, the calculation of the creatinine clearance could be a more efficient indicator for the screening of kidney disease in hypertensive patients, or at least a sign that these patients require a closer follow up when it is down normal levels.

Even considering levels of creatinine clearance below $60 \mathrm{ml} / \mathrm{min} / \mathrm{m}^{2}$ BS, this parameter seems to be more sensitive than microalbuminuria in detecting renal damage in the patients included in this study, a fourth of the hypertensive patient, with no clinical evidences of complications or symptoms (even with normal values of creatinine, and apparently appropriate control of BP figures) had a calculated creatinine clearance below this level.

Although GFR between 60 and $89 \mathrm{ml} / \mathrm{min} / \mathrm{m}^{2}$ BS is considered a mild renal damage, this may be a signal that treatment adjustment is needed in order to prevent the influence of other RF that must be identified, controlled, and if possible, eliminated, it should also be the moment to set a proper follow up of the progression of the renal damage in these patients (12).

The fact that many patients had a normal creatinine with a reduce calculated creatinine clearance below $90 \mathrm{ml} / \mathrm{min} / \mathrm{m}^{2}$ BS and that in most cases microalbuminuria was negative, suggests that the clearance calculated by Cockcroft-Gault formula (or any other that allows the estimation of creatinine clearance) could be a reliable alternative in the follow up of hypertensive patients.

The HARVEST study (19) detected positive microalbuminuria in only $10 \%$ of hypertensive patients; the investigators explain this low percentage because the microalbuminuria in non-diabetic patients with hypertensive vascular repercussion microalbuminuria is more a predictor of cardiovascular event than a marker of renal damage.

Some authors consider that the hidden renal illness with clearance values below $60 \mathrm{ml} / \mathrm{min} / \mathrm{m}^{2}$ BS is relatively frequent mainly in women older than 65 years-old, they consider that this constitutes an increment of total cardiovascular risk and early intervention, with stricter therapeutic objectives of the main vascular RF, as HBP, proteinuria, hyperlipidemia, obesity etc., could modify the progression of early kidney damage as well as the cardiovascular repercussion (5).

Ferrante and Virgolini (20) in the national survey on prevalence of RF of cardiovascular disease in Argentina, found that $40 \%$ of hypertensive patients had moderate risk, $35 \%$ high and only $25 \%$ had low risk, Hajjar and Kotchen $(21,22)$ in a study on treatment and control of BP found similar results, $20 \%$ of patients classified as low risk and $40 \%$ as moderate or high. In this study according to the initial stratification only $21 \%$ of patients were classified as high risk, however, after considering the evaluation carried out during the investigation more than three quarters of them could be considered as high risk. These results suggest that the risk can be high even in asymptomatic, apparently well treated and controlled patients, for that reason it is important that the treatment goes according to real risk and not only aiming to the control of BP figures.

Ortiz Brown et al. (15) in a study carried out in Madrid, found similar results when they made a new stratification of the hypertensive patients with medical treatment, the new stratification found that the $75 \%$ of them had renal damage and were treated as low risk patients.

Most patients included in this study classified as low risk at the beginning, had renal damage in the same proportion than those stratified as high risk, this was due to a faulty stratification using the absolute values of creatinine instead of calculation of clearance and the fact that the echocardiogram is not a usual study in non-complicated hypertensive patients, this implies, that not all low risk patients are in their actual stratification and that there is not an appropriate perception of risk not by the patients nor by the physicians, to keep this possibility on mind can be crucial for rectifying the treatment, the falling of creatinine clearance below $90 \mathrm{ml} / \mathrm{min} / \mathrm{m}^{2}$ BS could be a good reference point to make a deeper evaluation of the total cardiovascular risk, mainly in patients with a longer time of evolution.

The present study has the limitation of a relatively small sample, because of the need to carry out all planned studies in a short period of time; nevertheless, this can be compensated by the high prevalence of the HBP in the studied population. By the other hand an important study as kidney ultrasound was not included and this could have reinforced the results.

\section{CONCLUSION}

Although it could not be demonstrated a direct relationship between the risk stratification and the presence of renal damage, it was found that the hypertensive patients, even without evidence of clinical complications, had undetected renal affectation, this implies an increment of total cardiovascular risk and points out that the treatments in the majority of cases were inadequate according to the actual risk stratification. Thus, subclinical renal damage should necessitate for more aggressive modifications of standard CV risk factors. The absolute benefits of intensive BP lowering in these high-risk individuals (with subclinical CKD) are additional and large.

\section{REFERENCES}

1. Weinberger MH. Salt sensitivity is associated with an increased mortality in both normal and hypertensive humans. J Clin Hypertens 2014;4:274-6.

2. Curto S, Prats O, Ayeteran R. et al. RevMed Uruguay 2014;20:61-71.

3. Carlos ZSM, Hans MO, Maritza FO. Prevalencia de enfermedad renal crónica en centros urbanos de atención primaria. Rev Med Chile 2011;139:1176-84

4. Ministerio de Salud Pública. Anuario Estadístico de Salud 2016 [internet]. La Habana: Dirección Nacional de Registros Médicos y Estadísticas de Salud 2017.

5. Martín de FAL, Aguilera GL, Fuster CV. Enfermedad cardiovascular enfermedad renal y otras enfermedades crónicas. Es necesaria una intervención más temprana en la enfermedad renal croónica. Aten Primaria 2009;41(9):511-4.

6. Coresh J, Astor BC, Greene T, et al. Prevalence of chronic kidney disease in the adult US population: Third national health and nutrition examination survey. Am J Kidney Dis 2003;41:1-12.

7. Otero A, Abelleira A, Camba MJ, et al. Prevalencia de insuficiencia renal oculta en la provincia de Orense. Nefrología 2003.

8. Simal F, Martin EJC, Bellido J, et al. Prevalencia de la enfermedad renal crónica leve y moderada en población general. Estudio Hortega. Nefrología 2004;24:329-37.

9. Almirall J, Vaqueiro M, Antón E, et al. Prevalencia de la insuficiencia renal en la población general mayor de 64 años y episodios cardiovasculares. Nefrología 2005;6:655-62.

10. Fox CS, Larson MG, Leip EP, et al. Predictors of new-onset kidney disease in a community-based population. JAMA 2004;291:844-50.

11. Cairo SG, Rodríguez MD, Batista Hernández NE, et al. Estratificación de riesgo y complicaciones isquémicas en pacientes hipertensos. Medicent Electrón 2016;20(3).

12. K/DOQI clinical practice guidelines for chronic kidney disease evaluation classification, and stratification. Kidney Disease Outcome Quality Initiative. Am J Kidney Dis 2002;39:S1-266.

13. The Task Force for the management of arterial hypertension of the European Society of Hypertension and of the European Society of Cardiology. 2013 $\mathrm{ESH} / \mathrm{ESC}$ Guidelines for the management of arterial hypertension. 
14. INHEM. Segunda encuesta nacional de factores de riesgo 2012.

15. Soto CV. Prevalencia de hipertensión arterial en la ciudad de Chiclayo en el 2000: estudio poblacional. Rev Soc Peru Med Interna 2001;14(3):153-8.

16. Ortiz MH, Vaamonde MRJ, Zorrilla TB, et al. Prevalencia, grado de control y tratamiento de la hipertensión arterial en la población de 30 a 74 años de la comunidad de madrid. Estudio PREDIMCKD Rev Esp Salud Pública 2011;85:329-38.

17. Weber MA, Jamerson K, Bakris GL, et al. Effects of body size and hypertension treatments on cardiovascular event rates: subanalysis of the ACCOMPLISH randomised controlled trial. The Lancet 2013;381(9866):537-45.

18. Ruilope LM, Segura J, Campo C, et al. Renal participation in cardiovascular risk in essential hypertension. Expert Rev Cardiovasc Ther 2013;1(2):309-15

19. Echeverría RF, Camacho RO, Carbajal HA, et al. Prevalencia de la hipertensión arterial en La Plata. Medicina 2010;48:22-8.

20. The HARVEST Study Group. Heart rate as a predictor of development of sustained hypertension in subjects screened for stage 1 hypertension the HARVEST Study. J Hypertens 2006:24(9):1873-80.

21. Ferrante D, Virgolini M. Encuesta Nacional de Factores de Riesgo 2005 resultados principales. Prevalencia de factores de riesgo de enfermedades cardiovasculares en la Argentina. Rev Argent Cardiol 2011;75:20-9.

22. Hajjar I, Kotchen T. US Trends in Prevalence, Awareness, Treatment, and Control of Hypertension, 1988-2000. JAMA 2013;290:199-206. 